DOI: 10.12731/wsd-2017-4-2-167-179

УДК 577.486 (082)

\title{
ОЦЕНКА ФЛОРИСТИЧЕСКОГО И ФИТОЦЕНОТИЧЕСКОГО РАЗНООБРАЗИЯ ЭКОТОНОВ ВОДОХРАНИЛИЩА ЦАГАН-НУР
}

\author{
Уланов Н.Э., Шаглинов П.А., Лиджиева Н.Ц.
}

Цель. Одной из важнейтих биосферных функиий мировой сети водно-наземных экотонов является роль хранителей и создателей биологического разнообразия [1-7]. В условиях высокой аридности территории Калмыкии экотонные системы «вода-суша» являются важными ландшафтными резерватами сохранения степной и пустынной биоты. В связи этим целью исследования было изучение биоразнообразия растительности экотонных систем «вода-суша» на примере водохранилища Цаган-Нур, расположенного в Сарпинской депрессии Прикаспийской низменности.

Материалы и методы. Методической основой данного исследования является теория экотонной кониетции, согласно которой на побережье водоема выделяются блоки (участки), испытывающие различное воздействие водного объекта. Полевые исследования проведены во время вегетационного периода 2017 г. и включали выполнение топоэкологического профилирования со стандартным геоботаническим описанием.

Результаты. В результате геоботанического обследования экотона «вода-суша» побережья водохранилища Цаган-Нур были описаны состав и структура растительности, выполнены флористический и фитоценотический анализы. Выявлено, что видовой состав растительности водохранилища Цаган-Нур представлен 135 видами выстих растений, относящихся к 26 семействам и 91 родам. Преобладающие жизненные формы растений, встреченные в экотонной системе «вода-суша» побережья водохранилища Цаган-Нур, представлены монокарпическими травами (54,3\%). Преобладающим экотипом в экотонной системе побережья являются эвксерофить - 32,6\%.

Заключение. Таким образом, важной задачей экологических исследований водоемов и их побережий является разработка природоохранных мер для сохранения биоразнообразия пустынно-степной биоты.

Ключевые слова: водохранилища; экотоны; флора; фитоценоз. 


\title{
THE EVALUATION OF FLORISTIC AND PHYTOCENOTIC DIVERSITY OF ECOTONS OF THE TSAGAN-NUR RESERVOIR
}

\author{
Ulanov N.E., Shaglinov P.A., Lidzhieva N.Ts.
}

Background: One of the most important biosphere functions of the world network of water-terrestrial ecotones is the role of custodians and creators of biological diversity [1-7]. In conditions of high aridity of the territory of Kalmykia, ecotone systems "water-land" are important landscape reserves of conservation of steppe and desert biota. In connection with it, the goal of the present work was to study the biodiversity of vegetation of ecotone systems "water-land" using the example of the Tsagan-Nur reservoir, located in the Sarpin depression of the Caspian lowland.

Materials and methods: The methodological basis of this study is the theory of the ecotone concept, which implies that blocks (areas) are allocated on the coast of the reservoir experiencing different effects of a water object. Field studies were carried out during the growing season of 2017 and included the implementation of topoecological profiling with a standard geobotanical description.

Results: As a result of a geobotanical survey of the ecotone "water-land" on the coast of the Tsagan-Nur reservoir, the composition and structure of vegetation were described, floristic and phytocoenotic analyzes were performed. It was revealed that the species composition of the vegetation of the Tsagan-Nur reservoir is represented by 135 species of higher plants belonging to 26 families and 91 genera. The prevailing life forms of plants found in the ecotone system "water-land" on the shore of the Tsagan-Nur reservoir are represented by monocarpic grasses (54.3\%). The predominant ecotype in the ecotone system of the coast are eukserofity $-32.6 \%$.

Conclusion: Thus, the important task of ecological studies of water bodies and their coasts is the development of protection measures to conserve the biodiversity of desert-steppe biota.

Keywords: reservoirs; ecotones; flora; phytocenosis.

Экотоны (контактная полоса вдоль уреза воды) и экотонные системы, формирующиеся в результате воздействия вод водоемов являются частным случаем широко распространенных контактных зон. Они широко распространены повсюду, особенно в связи с интенсификацией антропогенных 
воздействий на природу. Для экотонных систем «вода-суша» характерно образование ряда блоков, испытывающих разное воздействие водоема по мере удаления от уреза воды [1]. Анализ имеющейся научной литературы по изучению экотонов $[1,8-14]$ позволил сделать вывод о необходимости выявления экотонных систем «вода-суша» как наиболее репрезентативных ландшафтных резерватов в условиях высокой аридности территории Калмыкии. В этой связи были проведены геоботанические исследования с целью изучения состава и структуры экотонной системы «вода-суша» побережья водохранилища Цаган-Нур, расположенного в южной части Сарпинской депрессии, оставленной древним руслом Волги на Прикаспийской низменности.

Объект исследований - водохранилище Цаган-Нур является самым крупным в цепи Сарпинских озер, ложе его вытянуто с севера на юго-восток на 45 км, средняя глубина 1.15 м. По данным космической съемки, на 2001 год

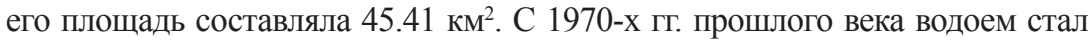
приемником сбросных вод орошаемых массивов, получающих воду из р. Волга по каналу ВР-1. Минерализация воды озера колеблется год от года (от 7 до 12 г/л) и по сезонам, в зависимости от количества осадков, объема, минерализации и времени поступления дренажно-сбросных вод $[13,15]$.

Методической основой данного исследования является теория экотонной концепции, согласно которой на побережье водоема выделяются блоки (участки), испытывающие различное воздействие водного объекта. Согласно этой концепции [1], выделяют 6 основных блоков: аквальный - акватория, с глубинами более 1.5-2.5 м (лишенная макрофитов); амфибиальный - литтораль, с периодическим обсыханием в период сработки вод водоемов, флуктуационный - ежегодно заливаемый участок побережья; динамический заливаемый неежегодно, в годы максимального половодья; дистантный - незаливаемая территория, но испытывающая воздействие неглубоко (до 3-5 м) залегающих грунтовых вод, и маргинальный - воздействие водоема передается через микроклимат предыдущих блоков (переходный к зональному).

Геоботанические исследования экотонной системы «вода-суша» были проведены в весенний и осенний периоды 2017 г. совместно с сотрудниками БНУ Республики Калмыкия «Институт комплексных исследований аридных территорий». На побережье водоема был заложен геоботанический профиль перпендикулярно урезу воды, от водоема вглубь побережья до зональной растительности. Профилирование побережий включало заложение пробных площадок описанием по стандартным геоботаническим методикам [16], которые включали: общее проективное покрытие (ОПП), проективное покрытие (ПП) видов, высота травостоя, обилие по шкале 
Друде, жизненность, фенофаза, степень и вид антропогенного воздействия, а также отбор растительных укосов на определение биологической продуктивности с площади $1 \mathrm{~m}^{2}$. При оценке фитоценотического разнообразия степных сообществ использовали принцип выделения фитоценозов, на основании выделения сообществ на основе общности биотопа, видового состава, доминировании видов. Для определения видовой принадлежности растений исследуемых фитоценозов использовали ряд определителей высших сосудистых растений. Латинские названия видов растений приведены по сводке С.К. Черепанова [17]. Анализ жизненных форм растений основан на подходах И.Г. Серебрякова [18], экологические типы растений выделены по Т.К. Горышиной [19]. В точках отбора данных на профиле проводилось определение высотных отметок и географических координат с помощью дистанционного геопозиционирования [20].

Ключевой участок расположен был расположен на левом побережье водохранилища Цаган-Нур, на расстоянии 1,5 км от плотины $\left(47^{\circ} 22^{\prime} 37\right.$ » с.ш., $45^{\circ} 11^{\prime} 37$ » в.д.). Были изучены и описаны четыре блока экотонной системы: флуктуационный, динамический, дистантный и маргинальный.

Протяженность флуктуационного блока составила 250 м от уреза воды, из них полоса осушки составила 110 м. Поверхность почвы, освобожденной от воды, была серого цвета, глинистая, сырая, такыровидная, практически полностью лишена растительности. Глубина залегания грунтовых вод в полосе осушки составила 0,7 м. За полосой осушки вглубь побережья произрастало солеросово-бассиевое сообщество (Bassia hirsuta+Salicornia perennans). Грунтовые воды залегали здесь на глубине 1,3 м. Общее проективное покрытие сообщества составило $15 \%$. В сообществе произрастают всего два вышеперечисленных вида с проективным покрытием более 7\% каждый. Это однолетние виды, переносящие высокий уровень засоления почвы. Воздушно-сухой вес фитомассы в данном блоке составило 95 г/ $\mathrm{m}^{2}$.

Динамический блок, протяженностью 150 м, составляли две полосы растительности. В первой полосе, протяженностью 65 м, произрастало бассиево-солеросовое (Salicornia perennans +Bassia hirsuta), общим проективным покрытием 95\%. Глубина залегания грунтовых вод в данной полосе составила 1,6 м. Доминант сообщества - Salicornia perennans (ПП 40\%), субдоминант - Bassia hirsuta (ПП 35\%), единично встречались и другие однолетние галофиты: Suaeda salsa и Salsola soda. Максимальная высота основной массы травостоя - 40 см. Биологическая продуктивность в данной полосе составила 426 г/м². Во второй полосе данного блока произрастали петросимониево-лебедовое растительное сообщество (Atriplex tatarica 
+Petrosimonia oppositifolia) с общим проективным покрытием 65\%. Грунтовые воды залегали на глубине 2,3 м. Количество видов растений - 13 . Доминант сообщества - Atriplex tatarica, обилие по Друде которого сор ${ }_{1}$, субдоминант - Petrosimonia oppositifolia с обилием $\mathrm{sp}_{1-2}$. Остальные виды представлены в меньшем обилии. Это однолетние солянки: Bassia hyssopifolia, Atriplex prostrata, Salsola soda, Suaeda salsa и многолетние травы: Argusia sibirica, Vincetoxicum sibiricum. Из полукустарничков произрастал галомезофит Artemisia santonica, древесные формы растений были представлены подростом кустарника Tamarix laxa, высотой около $20 \mathrm{~cm}$. Воздушно-сухой вес фитомассы растений в данной полосе составил 307 г/ $\mathrm{M}^{2}$.

Дистантный блок начинался на расстоянии 400 м от уреза воды. В первой полосе растительности данного блока, протяженностью более 80 м, грунтовые воды в данном блоке залегали на глубине более 2,5 м. Здесь произрастали петросимониево-сведовые (Suaeda salsa - Petrosimonia oppositifolia + P.brachiata) сообщества. Количество встреченных в данном блоке видов - 11 , ОПП сообщества - $60 \%$. Доминант сообщества - однолетний галофит Suaeda salsa, обилие которого составляет половину всего проективного покрытия травостоя, обилие его по Друде - сор. . Субдоминанты сообщества - виды рода Petrosimonia. Из однолетних видов были отмечены: Salicornia perennans, Atriplex tatarica, Bassia hirsuta, Senecio vernalis, Polygonum aviculare, Suaeda acuminata. Многолетние виды представлены корневищным гипергалофитом Aeluropus littoralis, кустарники - проростками Tamarix laxa, высотой до 40 см. Биологическая продуктивность сообщества составила 92 г/м². Во второй полосе, протяженностью более 50 м, произрастали петросимониево-сантониннополынно-тамариксовые сообщества (Tamarix laxa - Artemisia santonica+Petrosimonia brachiata). Грунтовые воды залегали на глубине более 3 м. Количество видов - 10, ОПП - 60\%. Сообщество двухъярусное: первый ярус высотой до 3 м и сомкнутостью крон 0,6, был представлен кустарником Tamarix laxa. Второй ярус высотой до 50 см, представлен доминирующими видами: Petrosimonia brachiata с обилием по Друде сор ${ }_{2-3}$ и Artemisia santonica, с обилием $\mathrm{sp}_{2}$. Обилие остальных видов незначительно. Среди них большинство - многолетние травянистые растения: дерновинный галофит Puccinellia dolicholepis, мезофит Limonium caspium, полукустарник с глубоко проникающей корневой системой Alhagi pseudalhagi, а также длиннокорневищный ксерофит Argusia sibirica. Из однолетних видов были отмечены Atriplex prostrata, Polygonum novoascanicum, Lepidium ruderale. Воздушно-сухой вес фитомассы растений составил 125 г/M². 
Маргинальный блок начинается в 520 м от уреза воды. Здесь произрастали разнотравно-злаково-полынные сообщества (Artemisia lerchiana + A.santonica + A.pauciflora - Poaceta - Mixteherbosa). ОПП сообщества составило $50 \%$, количество видов растений - 20. Почвы и растительность приобретают зональный характер: происходит смена луговых почв на бурые пустынно-степные легкосуглинистые в комплексе с солонцами, появляется больше ксерофильных видов. Из полукустарничков произрастают Artemisia lerchiana, A. pauciflora, A.santonica, Potentilla bifurca, из полукустарников - Alhagi pseudalhagi, из многолетних злаков отмечены: Agropyron cristatatum, A.desertorum, Koeleria glauca, Stipa sareptana. Были отмечены и однолетние злаки: Anisantha tectorum, Eremopyrum triticeum. Разнотравье представлено в основном многолетними видами: Achillea leptophylla, A.nobilis, Dianthus polymorphus, Kochia prostrata, Phlomis pungens. Воздушно-сухой вес фитомассы растений в данном блоке составил 58 г/ $\mathrm{M}^{2}$.

Флористический анализ экотонной растительности водохранилища Цаган-Нур показал, что видовой состав представлен 135 видами высших растений, относящихся к 26 семействам и 91 родам. Самые многочисленные из них в видовом отношении семейства Chenopodiaceae (31), Asteraceae (20), Poaceae (20) и Brassicaceae (13). Остальные семейства представлены от 1 до 7 видов (табл. 1).

Таблица 1.

Распределение видов по семействам в экотонной системе «вода-суша» побережья водохранилища «Цаган-Нур»

\begin{tabular}{|c|c|}
\hline $\begin{array}{l}\text { Количество видов } \\
\text { в семействах }\end{array}$ & Название семейств с данным числом видов \\
\hline 31 & Chenopodiaceae \\
\hline 20 & Asteraceae, Poaceae \\
\hline 13 & Brassicaceae \\
\hline 7 & Caryophyllaceae \\
\hline 6 & Limoniaceae \\
\hline 4 & Boraginaceae, Lamiaceae, Rubiaceae \\
\hline 3 & Polygonaceae \\
\hline 2 & $\begin{array}{c}\text { Apiaceae, Cyperaceae, Fabaceae, Ranunculaceae, Rosaceae, } \\
\text { Scrophulariaceae, Tamaricaceae }\end{array}$ \\
\hline 1 & $\begin{array}{c}\text { Amaranthaceae, Asclepiadaceae, Convolvulaceae, Cuscu- } \\
\text { taceae, Frankeniaceae, Juncaceae, Liliaceae, Lythraceae, } \\
\text { Primulaceae }\end{array}$ \\
\hline
\end{tabular}


Большую часть растительности обследованных экотонов составляют монокарпические травы - 54,3\% (рис. 1).

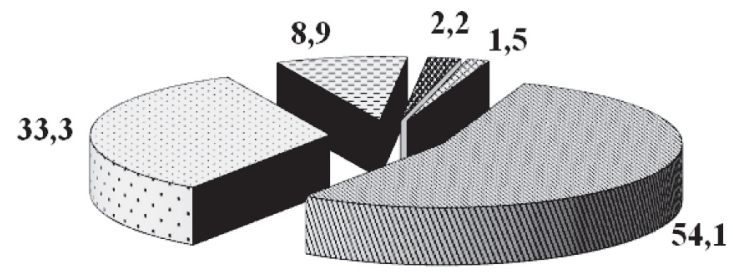

\section{ه монокарпические травы $\square$ поликарпические травы $\square$ полукустарнички 용 полукустарники 母 кустарникі}

Рис. 1. Жизненные формы растений в экотонной системе «вода-суша» побережья водохранилища Цаган-Нур
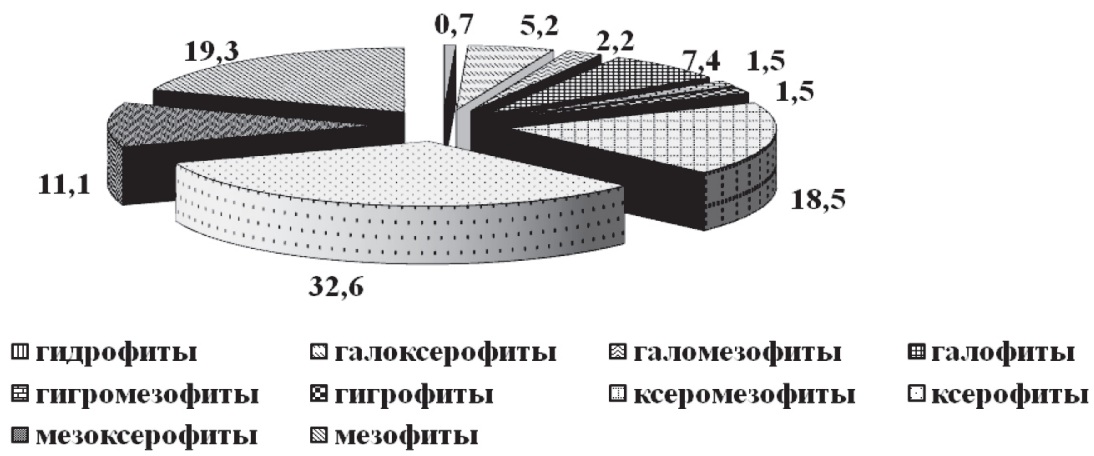

Рис. 2. Распределение экотипов раститений в экотонной системе «вода-суша» побережья водохранилища Цаган-Нур

Среди однолетних монокарпических трав встречаются: Alyssum desertorum, Eremopyrum orientale, E. triticeum, виды рода Atriplex (Atriplex aucheri, A.micrantha, A.prostrata и др.), Chenopodium album, из двулетних - Berteroa incana, Crepis tectorum, Lappula squarrosa, Lepidium perfoliatum. Многолетние травы составляют 33,3\% от общего числа видов растений: виды рода Achillea (A. leptophylla, A.nobilis), Bolboschoenus maritimus, Convolvulus arvensis, Dianthus polymorphus, Leymus ramosus, Carex stenophylla, виды рода Limonium (L.caspium, L. gmelinii, L.meyeri) и др. Полудревесные формы представлены полукустарниками и полукустарничками. Полукустарнички представлены 12 видами $(8,9 \%)$ от об- 
щего числа отмеченных растений. Это виды рода полыней: Artemisia austriaca, A.lerchiana, A.pauciflora, A.santonica, A.taurica, Camphorosma monspeliaca, Frankenia hirsuta, Halimione verrucifera, Kochia prostrata, Limonium suffruticosum и др. Полукустарники занимают 2,2\%: Alhagi pseudalhagi, Anabasis aphylla и Halocnemum strobilaceum. Древесные формы представлены кустарниками, на данной территории отмечено 2 вида (1,5\%) рода Tamarix - T.laxa и T.ramosissima.

Растительность экотонной территории водохранилища Цаган-Нур представлена 10 экологическими типами, из которых преобладают эвксерофиты - 32,6\% (Artemisia lerchiana, A. taurica, Atriplex aucheri и др.) (рис. 2). Эвмезофиты и переходные ксеромезофиты составляют 19,3\% и 18,5\% соответственно. 11,1\% приходится на мезоксерофиты, 7,4\% - на эвгалофиты, 5,2\% - галоксерофиты. 2,2\% составляют галомезофиты, по 1,5\% приходится на гигрофиты и галомезофиты, $0,7 \%$ - гидрофиты.

Таким образом, исследование показывает, что для экотонов водоемов засушливой зоны характерна множественность экологических ниш. Это обуславливает возможность совместного обитания экологически различных организмов, что способствует увеличению биологического разнообразия. В связи с этим важной задачей экологических исследований водоемов и их побережий является разработка природоохранных мер для сохранения биоразнообразия степной и пустынной биоты.

\section{Список литературы}

1. Залетаев В.С. Структурная организация экотонов в контексте управления / Под ред. В.С. Залетаева // Экотоны в биосфере. М.: РАСХН, 1997. С. 11-30.

2. Бобра Т.В. Ландшафтные экотоны Крыма // Биологическое и ландшафтное разнообразие Крыма: проблемы и перспективы. Научно-практический дискуссионно-аналитический сборник «Вопросы развития Крыма». Симферополь: Сонат, 1999. Вып.11. С. 31-33.

3. Подольский С.А. Значение экотонов для млекопитающих зоны влияния Зейского водохранилища // Экотоны в биосфере. М.: РАСХН, 1997. С. 138-148.

4. Новикова Н.М. Экосистемы экотонных ландшафтов речных дельт аридного пояса Евразии и их современная динамика // Экотоны в биосфере. М.: PACXH, 1997. C. 147-160.

5. Кузьмина Ж. В. Анализ изменений многолетних метеорологических характеристик для оценки динамики экосистем // Отчет ИПВ РАН по теме «Оценка трансформации природных комплексов под влиянием природных и антропогенных изменений вод суши». М.: ИВП РАН, 2005. С. 8-18. 
6. Ulanova S.S., Lidzhieva N. Th. Environmental monitoring of reservoir Deedhulsun and its adjacent areas // Biosciences biotechnology research asia, 2015, Vol. 12 (1), pp. 1017-1021.

7. Кулешова М.Е. Экологические каркасы // Охрана дикой природы. Москва, 1999. №14. C. 82-98.

8. Залетаев В.С. Экологически дестабилизированная среда (экосистемы аридных зон в изменяющемся гидрологическом режиме). М.: Наука, 1989. 150 с.

9. Неронов В.В. Развитие концепции экотонов и их роль в сохранении биологического разнообразия // Успехи современной биологии. 2001. Т.121. № 4. C. 323-336.

10. Антропогенные воздействия на водные ресурсы России и сопредельных государств в конце XX столетия. М.: Наука, 2003. 367 с.

11. Авакян А.Б. Многоликие водохранилища - феномен XX в. // Актуальные проблемы водохранилищ: Тез. докл. Ярославль: ИБВВ РАН, 2002. С.1-6.

12. Novikova N.M., Volkova N.A. Structure of the flora of the coasts in the area of influence of the reservoirs on the south of the european part of Russia // Arid Ecosystems, 2016, Vol. 6, No. 4, pp. 268-276.

13. Ulanova S.S. Ecological Monitoring of Caspian Lowlands Reservoirs in Kalmykia (Example of Tsagaan Nuur Reservoir) // Arid Ecosystems, 2015, Vol. 5, No. 2, pp. 66-75. ISSN 2079-0961.

14. Novikova N.M., Volkova N.A., Ulanova S.S., Shapovalova I.B., Vyshivkin A.A. Ecosystem responses to hydrological regime changes in the steppe zone // Arid ecosystems, 2011, Vol. 1, No. 3, pp. 142-148. ISSN 2079-0961.

15. Ulanova S.S. Ecological Passportization of Artificial Water Resources of Kalmykia // 13th International conference on salt lake research (ICSLR 2017): Book of abstracts, august 21-25. 2017. Ulan-Ude, Russia. Ulan-Ude, 2017. 24 p. ISBN 978-5-9793-1075-6.

16. Полевая геоботаника / Под общ. ред. Е.М. Лавренко и А.А. Корчагина. В 5 т. М.; Л.: Наука. 1959-1976. Т. 3. 1964.442 с.; Т.4. 1972. 336 с.

17. Черепанов С.К. Сосудистые растения России и сопредельных государств (в пределах бывшего СССР). Л.: Наука, 1995. 990 с.

18. Серебряков И.Г. Экологическая морфология растений. Жизненные формы покрытосеменных и хвойных. М.: Высш.шк., 1962.378 с.

19. Горышина Т.К. Экология растений. Москва: Высшая школа, 1979. 369 с.

20. Zolotokrylin A.N., Titkova T.B., Ulanova S.S. and Fedorova N.L. GroundBased and Satellite Investigation of Production of Pastures in Kalmykia. That Vary in Degree of Vegetation Degradation // Arid Ecosystems, 2013, Vol. 19, № 4, pp. 212-219. 


\section{References}

1. Zaletaev V.S. Strukturnaya organizatsiya ekotonov v kontekste upravleniya [Structural organization of ecotones in the context of management]. Ekotony $v$ biosfere [Ecotones in the biosphere]. M.: RAASHN, 1997, pp. 11-30.

2. Bobra T.V. Landshaftnye ekotony Kryma [Landscaping ecotones of the Crimea]. Biologicheskoe i landshaftnoe raznoobrazie Kryma: problemy i perspektivy. Nauchno-prakticheskiy diskussionno-analiticheskiy sbornik «Voprosy razvitiya Kryma» [Biological and landscape diversity of the Crimea: problems and perspectives. Scientific-practical discussion and analytical collection «Issues of the development of the Crimea»]. Simferopol: Sonat, 1999. issue.11. pp. 31-33.

3. Podol'skiy S.A. Znachenie ekotonov dlya mlekopitayushchikh zony vliyaniya Zeyskogo vodokhranilishcha [The importance of ecotones for mammals of the zone of influence of the Zeya reservoir]. Ekotony $v$ biosfere [Ecotones in the biosphere]. Moscow: RAASHN, 1997, pp. 138-148.

4. Novikova N.M. Ekosistemy ekotonnykh landshaftov rechnykh del't aridnogo poyasa Evrazii i ikh sovremennaya dinamika [Ecosystems of ecotone landscapes of the river deltas of the arid belt of Eurasia and their modern dynamics]. Ekotony $v$ biosfere [Ecotones in the biosphere]. Moscow: RAASHN, 1997, pp. 147-160.

5. Kuz'mina Zh.V. Analiz izmeneniy mnogoletnikh meteorologicheskikh kharakteristik dlya otsenki dinamiki ekosistem [Analysis of changes in multi-year meteorological characteristics for the assessment of ecosystem dynamics]. Otchet IPV RAN po teme "Otsenka transformatsii prirodnykh kompleksov pod vliyaniem prirodnykh $i$ antropogennykh izmeneniy vod sushi» [Report of the IPV RAS on the topic «Assessment of the transformation of natural complexes under the influence of natural and anthropogenic changes in land waters»]. Moscow: IVP RAS, 2005, pp. 8-18.

6. Ulanova S.S., Lidzhieva N. Th. Environmental monitoring of the reservoir Deed-hulsun and its adjacent areas. Biosciences biotechnology research asia, 2015, Vol. 12 (1), pp. 1017-1021.

7. Kuleshova M.E. Ekologicheskie karkasy [Ecological frameworks]. Okhrana dikoy prirody [Protection of wild nature]. Moscow, 1999. №14, pp. 82-98.

8. Zaletaev V.S. Ekologicheski destabilizirovannaya sreda (ekosistemy aridnykh zon $v$ izmenyayushchemsya gidrologicheskom rezhime) [Ecologically destabilized environment (ecosystems of arid zones in a changing hydrological regime)]. M.: Science, 1989. 150 p.

9. Neronov V.V. Razvitie kontseptsii ekotonov i ikh rol' v sokhranenii biologicheskogo raznoobraziya [Development of the concept of ecotones and their role in conserving biological diversity]. Uspekhi sovremennoy biologii [Progress in modern biology]. 2001. Vol.121. № 4, pp. 323-336. 
10. Antropogennye vozdeystviya na vodnye resursy Rossii i sopredel'nykh gosudarstv $v$ kontse XX stoletiya [Anthropogenic impacts on the water resources of Russia and neighboring countries at the end of the 20th century]. M.: Science, 2003. $367 \mathrm{p}$.

11. Avakyan A.B. Mnogolikie vodokhranilishcha - fenomen XX v. [The many-faced reservoirs are a phenomenon of the 20th century]. Aktual'nye problemy vodokhranilishch: Tez. dokl [Actual problems of reservoirs: Tez. doc.]. Yaroslavl: IBVV RAS, 2002, pp. 1-6.

12. Novikova N.M., Volkova N.A. Structure of the flora of the coasts in the south of the european part of Russia. Arid Ecosystems, 2016, Vol. 6, No. 4, pp. 268-276.

13. Ulanova S.S. Ecological Monitoring of Caspian Lowlands Reservoirs in Kalmykia (Example of Tsagaan Nuur Reservoir). Arid Ecosystems, 2015. Vol. 5, No. 2, pp. 66-75. ISSN 2079-0961.

14. Novikova N.M., Volkova N.A., Ulanova S.S., Shapovalova I.B., Vyshivkin A.A. Ecological responses to the hydrological regime of changes in the steppe zone. Arid ecosystems, 2011, Vol. 1, No. 3, pp. 142-148. ISSN 2079-0961.

15. Ulanova S.S. Ecological Passportization of Artificial Water Resources of Kalmykia. 13th International Conference on Saline Research (ICSLR 2017): Book of abstracts, august 21-25 2017. Ulan-Ude, Russia. Ulan-Ude, 2017, 24 p. ISBN 978-5-9793-1075-6.

16. Polevaya geobotanika [Field geobotany]. In the 5 th century. M.; L.: Science. 1959-1976. Vol. 3. 1964. 442 p.; Vol. 4. 1972. 336 p.

17. Cherepanov S.K. Sosudistye rasteniya Rossii i sopredel'nykh gosudarstv [Vascular plants of Russia and neighboring countries]. L.: Science, 1995. 990 p.

18. Serebryakov I.G. Ekologicheskaya morfologiya rasteniy. Zhiznennye formy pokrytosemennykh $i$ khvoynykh [Ecological morphology of plants. Life forms of angiosperms and conifers]. M.: Higher School, 1962. 378 p.

19. Goryshina T.K. Ekologiya rasteniy [Ecology of plants]. Moscow: Higher School, 1979. $369 \mathrm{p}$

20. Zolotokrylin A.N., Titkova T.B., Ulanova S.S. and Fedorova N.L. GroundBased and Satellite Investigation of Production of Pastures in Kalmykia. That Vary in Degree of of Vegetation Degradation. Arid Ecosystems,2013, Vol. 19, No. 4, pp. 212-219.

\footnotetext{
ДАННЫЕ ОБ АВТОРЕ

Уланов Наран Эрдниевич, магистрант

Федеральное государственное бюджетное общеобразовательное учреждение выстего образования «Калмыикий государственный университет имени Б.Б. Городовикова»
} 
ул. Пушкина, 11, г. Элиста, 358009, Российская Федерациия bio@kalmsu.ru

\section{Шаглинов Павел Анатольевич, магистрант}

Федеральное государственное бюджетное общеобразовательное учреждение высшего образования «Калмыцикий государственнылй университет имени Б.Б. Городовикова»

ул. Пушкина, 11, г. Элиста, 358009, Российская Федеращчия bio@kalmsu.ru

Лиджиева Нина Цереновна, д.б.н., профессор, заведующий кафедрой общей биологии и физиологии Федеральное государственное бюджетное общеобразовательное учреждение высшего образования «Калмыцкий государственный университет имени Б.Б. Городовикова»

ул. Пушкина, 11, г. Элиста, 358009, Российская Федерачия for-lidjieva@yandex.ru

\section{DATA ABOUT THE AUTHORS}

Ulanov Naran Erdnievich, Graduate Student

Kalmyk State University named after B.B. Gorodovikova 11, Pushkin Str., Elista, 358009, Russian Federation

bio@kalmsu.ru

ORCID: 0000-0002-5032-3946

Shaglinov Pavel Anatol'evich, Graduate Student

Kalmyk State University named after B.B. Gorodovikova 11, Pushkin Str., Elista, 358009, Russian Federation bio@kalmsu.ru

ORCID: 0000-0001-8981-485X

Lidzhieva Nina Tserenovna, Doctor of Biology, Professor, Head at the General Biology and Physiology Department Kalmyk State University named after B.B. Gorodovikova 11, Pushkin Str., Elista, 358009, Russian Federation for-lidjieva@yandex.ru SPIN-code: 3661-2682 ORCID: 0000-0003-2668-698X 